\title{
INOVAÇÃO SOCIAL: NEGÓCIOS DE IMPACTO E SEU CENÁRIO NO ESTADO DO CE.
}

Gabriela Sousa $^{1}$

Mariana Menezes ${ }^{1}$

${ }^{1}$ Universidade de Fortaleza - UNIFOR 


\section{INOVAÇÃO SOCIAL: NEGÓCIOS DE IMPACTO E SEU CENÁRIO NO ESTADO DO CE.}

Este estudo objetivou em detectar de que maneira está delineado os perfis das empresas que trabalham com negócios com impacto social no estado do Ceará, procurando trazer uma representação desses negócios na região, bem como estruturar um perfil, explorar qual o principal impacto realizado pelas empresas e como são as suas formas de trabalho. A pesquisa é qualitativa e exploratória, para isso, foi usado no método de coleta de dados um roteiro de entrevista semiestruturado elaborado junto com o referencial teórico levantado sobre negócio sociais e base da pirâmide. Duas empresas participaram da entrevista e o cenário desses negócios foi apresentado, destacando a estruturação do perfil dos negócios, suas limitações, seu público-alvo e de que forma a organização consegue mensurar o impacto proposto. Contudo, esse estudo representa o cenário da inovação social através da representação dos negócios de impacto social presentes no Ceará.

Palavras-chave: Inovação social. Negócios Sociais. Base da Pirâmide. Negócios com Impacto Social.

\section{Introdução}

No século XVIII tinha-se aproximadamente 1 bilhão de habitantes na terra, três séculos depois, tem-se uma população por volta de 7 bilhões de habitantes, segundo dados do Banco Mundial (2012), com previsão de chegar em 8,6 bilhões em 2030 (ONU, 2017). Malthus (1888) já relatava em seu estudo sobre crescimento populacional, que enquanto a produção de alimentos cresce em P.A. (progressão aritmética), a nossa população cresce em P.G. (progressão geométrica). Quanto mais pessoas começam a habitar no planeta, mais o homem começa a retirar recursos da natureza para a sobrevivência, levando assim a um momento em que ela não conseguirá ofertar recursos para a sobrevivência de todos (MALTHUS, 1888).

A Organização Mundial da Saúde e o Fundo das Nações Unidas para a Infância publicaram o relatório "Progress on Sanitation and Drinking-water: 2010 Update" informando que 2,6 bilhões de habitantes no mundo não tem acesso a serviços de saneamento básico e 884 milhões não têm acesso à água tratada (WHO; UNICEF, 2010). O relatório "Progress on Drinking Water, Sanitation and Hygiene: 2017", informa que 4,5 bilhões carecem de saneamento seguro e 2,1 bilhões de habitantes ainda não têm acesso a água potável em todo mundo (WHO; UNICEF, 2017). Em um curto período de tempo, depois do lançamento do estudo de 2010, apresenta um aumento na falta de recursos, o que de princípio acaba sendo bastante significativa para a população mundial. Uma vez que esses estudos deixam evidente que o crescimento populacional afetará a dificuldade de proporcionar recursos e qualidade de vida para todos.

O mercado e as políticas governamentais carecem de modelos e incentivos para resolver os problemas no mundo, a inovação social envolve todos os setores da sociedade e dessa forma ela procurar sanar por meio da cooperação e da colaboração a economia social com os problemas existentes (MURRAY; CAULIER-GRICE; MULGAN, 2010). Questões como água e saneamento, perpetuam muito mais os países emergentes devido ao desenvolvimento 
dessas economias, dados do Banco Mundial (2012) informam que ainda existe uma população que vive com menos de 2 dólares por dia, que a maior parte tem dificuldade ao acesso dos bens de consumo por faltar recurso para sobrevivência no seu dia-a-dia.

Como uma das formas de tentar solucionar o problema, surge-se o termo desenvolvimento sustentável, que foi citado pela primeira vez no Relatório Brundtland em 1987 pela Comissão Mundial sobre Meio Ambiente e Desenvolvimento das Nações Unidas (1988), na qual explica que o desenvolvimento sustentável "é aquele que atende as necessidades das gerações atuais sem comprometer a capacidade das gerações futuras de atenderem às suas necessidades e aspirações" (COMISSÃO MUNDIAL SOBRE MEIO AMBIENTE E DESENVOLVIMENTO, 1988, p. 46). O relatório apresentava que a produção de bens seria contraditória ao conceito do termo, devido às ações realizadas ao meio ambiente, o mesmo propõe medidas baseadas no desenvolvimento sustentável para prevenção do meio ambiente cuidando dos recursos naturais.

Em 2015, diante de 193 países-membros das Nações Unidas, seus representantes políticos aderiram a Agenda 2030 para o Desenvolvimento Sustentável, na qual apresenta os 17 Objetivos de Desenvolvimento Sustentável (ODS), a agenda expressa o comprometido com as devidas mudanças climáticas e sociais que precisaram ser trabalhadas e desenvolvidas até a sua data final, são mudanças como a erradicação da pobreza, redução das desigualdades sociais, a busca pela educação de qualidade, fome zero e agricultura sustentável, entre outros (PNUD, 2018).

Diante dos temas como a falta de recursos naturais e o aumento das desigualdades, ambos são temas que requerem espaço para discussões e principalmente para o desenvolvimento de soluções que possam contribuir para a sociedade como um todo. Dessa forma, nos últimos anos vem se apresentado um novo modelo para o desenvolvimento de soluções através de negócios que tenha menos impacto no planeta, denominado como "negócios sociais".

A inovação social pode acontecer em todos os setores, fazendo com que novas ideias de produtos, serviços e modelos sejam criados a partir disso e assim possam atender as necessidades sociais (MURRAY; CAULIER-GRICE; MULGAN, 2010).

Jappe (2013) em seu estudo sobre os "Fatores contributivos e limitadores para negócios sociais no sudeste e sul do Brasil", realizado em 2013, relata que esse novo tipo de empresa tem como finalidade "a resolução de desafios sociais, de forma financeiramente viável". A criação desse novo modelo de negócios social de impacto, tem diversas terminologias que serão abordadas mais adiante, mas apesar de ser um novo campo de estudo, o termo "negócios sociais" ainda não tem uma definição em que possa ser trabalhado como única (COMINI, BARKI, AGUIAR, 2012).

Dessa forma o estudo propõe-se a responder a seguinte questão de pesquisa: De que maneira a inovação social está sendo vivenciada nos negócios com impacto social no Ceará? Devido a necessidade de desenvolvimento de novos modelos de negócios com impacto social, o estudo se justifica pelo desenvolvimento do perfil desses negócios no estado, contribuindo assim para as pesquisas acadêmicas sobre a temática. O presente trabalho tem como objetivo: identificar de que maneira está delineado o perfil dos negócios com impacto social no estado.

Este artigo está constituído por cinco capítulos, o primeiro é formado pela introdução, que apresentou uma contextualização do artigo, compondo com isso a justificativa do estudo, 
questão de pesquisa e objetivo. Em seguida é apresentado a metodologia do estudo. No terceiro capítulo é abordada uma revisão da literatura sobre o contexto dos negócios sociais e base da pirâmide. O quarto capítulo é apresentado a análise dos resultados e o artigo finaliza com o quinto capítulo sobre as considerações finais do estudo.

\section{Metodologia}

O presente estudo caracteriza-se como uma pesquisa qualitativa e exploratória. Segundo Creswell (2010, p. 206) a pesquisa qualitativa "emprega diferentes concepções filosóficas; estratégias de investigação e método de coleta, análise e interpretação dos dados", ela se caracteriza por usar estratégias de investigação que são escolhidas e analisadas pelo pesquisador. Segundo Gil (2012, p. 27), "as pesquisas exploratórias têm como principal finalidade desenvolver, esclarecer e modificar conceitos e ideias, tendo em vista a formulação de problemas mais precisos ou hipóteses pesquisáveis para estudos posteriores".

O tipo de coleta de dados a ser utilizado na pesquisa, é a entrevista, em que o pesquisador leva a entrevista frente a frente com os participantes, envolvendo questões não estruturadas (perguntas abertas), que tem o intuito de suscitar as falas dos participantes (CRESWELL, 2010, p. 214).

Um roteiro de entrevista, com 16 perguntas abertas, fora criado e baseado de acordo com as referências que relatam sobre a estruturação de um perfil, tipos de impacto dos negócios com impacto social e a apresentação de seus trabalhos (MAPA, 2014; ARTEMÍSIA, 2017; IDIS, 2018; PLANO, 2011).

As inovações sociais tem a ver como as organizações que buscam inovar em seus produtos e serviços, procurando novas formas de adequação e aprimoramento que podem ocorrer na gestão de processos, elas são motivadas pela missão social e pelo seu valor (MURRAY; CAULIER-GRICE; MULGAN, 2010). Dessa forma, o critério de classificação para a escolha das empresas se deu através de informações que estavam presentes em seus canais de comunicação e através de palestras e eventos que apresentaram características de negócios com impacto social e negócios sociais.

No total 2 empresas participaram desse estudo, nas participações, em uma empresa foi possível fazer a gravação do áudio, para em seguida ser realizada uma transcrição posteriormente, na outra empresa, as questões foram respondidas pela entrevistadora a mão, as anotações foram repassadas para um documento Word. Segundo Creswell (2010, p. 216) os pesquisadores podem registrar informações das entrevistas com anotações escritas à mão, áudio ou em vídeo.

O roteiro elaborado foi aplicado nas entrevistas com as fundadoras das empresas. Inicialmente foi explicado o objetivo da pesquisa, as entrevistadas receberam a garantia da devolução dos dados obtidos no estudo. As entrevistas aconteceram no período de mais disponibilidade das fundadoras, no final de novembro de 2018, com duração de aproximadamente 30 minutos. Após a aplicação das perguntas e da passagem dos dados para um documento em Word, as informações foram tabuladas em três quadros e analisadas nos resultados da pesquisa. 


\section{Revisão da literatura}

\subsection{Negócios sociais}

O termo negócios sociais começou a ganhar destaque depois que Muhammad Yunus recebeu o Prêmio Nobel da Paz, em 2006, pela criação do Grameen Bank, com intuito de facilitar o microcrédito na região de Bangladesh, emprestando dinheiro para as pessoas saírem da pobreza tentando reduzir a vulnerabilidade existente no país, Muhammad Yunus é fundador do próprio banco e de outros negócios sociais (ROSOLEN; TICOSKI; COMINI, 2015).

O professor universitário já define em seu livro sobre "A empresa social e o futuro do capitalismo" que a "empresa social", ou melhor, o "negócio social" não possa ser categorizado pela maximização de lucros, como a maioria das empresas existentes são classificadas, para isso é necessário um novo tipo de empresa que não seja voltada apenas pela lucratividade do capitalismo, mas que ela possa incluir em seus propósitos a resolução de problemas sociais e ambientais, de tal forma que possam oferecer produtos e serviços com preços justos a realidade de seus consumidores (YUNUS, 2008, p. 35).

O termo negócios sociais têm sido conceituados de diversas formas em vários países e autores como: empresa social, negócios sociais, negócios com impacto social, negócios inclusivos, negócios de impacto, negócios com a base da pirâmide, entre outros (YUNUS, 2008; BARKI, 2015). O termo se diversifica devido a maneira como ela é trabalhada pelas realidades dos autores pelo mundo, tanto em países emergentes, quanto em países desenvolvidos (BARKI, 2013, p. 22).

Apesar dos negócios sociais se assemelharem muito com as ONG's (Organizações não Governamentais) e sociedade civil, Barki (2015) descreve que a diferença está na sustentabilidade financeira que a empresa procura, para não depender de doações e qualquer outro tipo de recurso que possa ser utilizado na empresa como forma de subsistência, elas são empresas que apresentam uma mesclagem tanto com um propósito financeiro como social.

Gomides (2018) relata que são empresas que intercalam entre o segundo setor (empresas privadas) e o terceiro setor (ONG's e etc.), conhecido como setor 2,5 (dois e meio), o que dá luz ao nome dos negócios sociais, são empresas que visam o lucro, mas também procuram fazer impacto.

Figura 1 - Setor Dois e Meio.

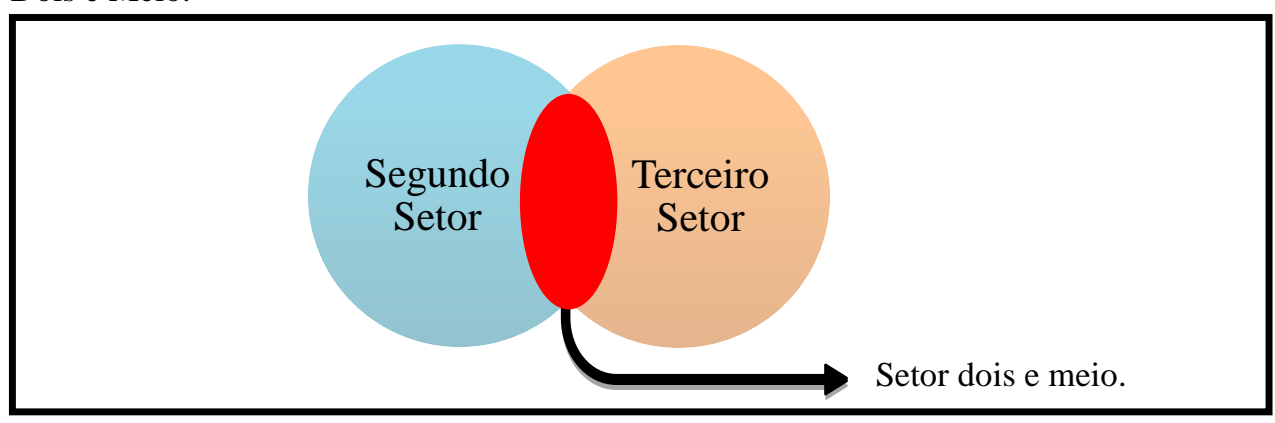

Fonte: Alves (2018).

Entretanto, Porter e Kramer (2011) argumentam que o propósito não é exclusividade dos negócios sociais, os autores já propõe o conceito de "princípio do valor compartilhado", 
que está ligada a geração de valor econômico como condição de fazer o mesmo para a sociedade, mas encarando os problemas sociais, ambientais e econômicos, procurando aumentar a sua competitividade no mercado simultaneamente.

A criação de valor econômico que os autores relatam, destaca-se por apresentar um capitalismo com um objetivo mais voltado para o social, fazendo com que possa ser construído uma evolução do modelo capitalista, para que sejam realizadas novas maneiras de aperfeiçoar produtos, mercados e empresas (PORTER; KRAMER, 2011).

Outro ponto para poder diferenciar os negócios sociais, é o modelo dos negócios de baixo custo, criado por empresas que já estão presentes no mercado, Yunus et al (2015) explicam que esse modelo de empresa, tem o intuito de criar relações com seu consumidor. A seguir apresenta-se uma tabela em que Yunus et al (2015) diferenciam esses dois modelos de negócios:

Quadro 1 - Como negócios sociais diferem de negócios de baixo custo.

\begin{tabular}{|c|c|c|}
\hline & Baixo custo & Social \\
\hline \multirow{4}{*}{$\begin{array}{l}\text { Proposição } \\
\text { de valor }\end{array}$} & \multicolumn{2}{|c|}{ OBJETIVO } \\
\hline & $\begin{array}{l}\text { Obter lucros melhorando o acesso a } \\
\text { produtos e serviços. }\end{array}$ & $\begin{array}{l}\text { Melhorar acesso a produtos e serviços } \\
\text { essenciais de forma financeiramente } \\
\text { sustentável. }\end{array}$ \\
\hline & \multicolumn{2}{|c|}{ FOCO } \\
\hline & Produtos e serviços de baixo preço. & Soluções acessíveis a problemas sociais. \\
\hline \multirow{4}{*}{$\begin{array}{c}\text { Fonte de } \\
\text { valor }\end{array}$} & \multicolumn{2}{|c|}{ OPERAÇÕES } \\
\hline & $\begin{array}{l}\text { Reconfigurar a cadeia de suprimentos da } \\
\text { produção para reduzir custos. }\end{array}$ & $\begin{array}{l}\text { Reconfigurar a distribuição da cadeia de } \\
\text { suprimentos para atingir consumidores-alvo. }\end{array}$ \\
\hline & \multicolumn{2}{|c|}{ PARCERIAS } \\
\hline & $\begin{array}{c}\text { Criadas em colaboração com organizações } \\
\text { que maximizam lucros. }\end{array}$ & $\begin{array}{l}\text { Requer ser criada em colaboração com } \\
\text { terceiros que tenham como objetivo o bem- } \\
\text { estar social. }\end{array}$ \\
\hline
\end{tabular}

Fonte: Adaptada de Yunus et al (2015).

Os negócios sociais conseguem fazer uma ligação com a inovação social, porque ao desenvolver e implementar novos produtos, serviços ou modelos, a inovação social procura atender as deficiências sociais existentes, que podem partir da iniciativa da sociedade civil ou de empresas, criando produtos que atendam o individual e o coletivo (COMMISSION, 2013).

É compreensível que os negócios de baixo custo apresentem um produto barato, elaborado justamente para o mercado em que se quer atingir, tendo como principal foco a redução de diversos pontos para poder potencializar os lucros nas vendas. Porém os negócios sociais, procuram uma forma de apresentar o produto ou o serviço de maneira sustentável tendo como foco a resolução dos problemas sociais de maneira inovadora e sustentável, buscando reconfigurar a cadeia de suprimentos a qual pertence. 


\subsection{Base da Pirâmide}

Barki (2013, p. 22-23) fundamenta a terminologia "base da pirâmide", explicando que não existe um consenso sobre sua definição, o autor relata que a maioria dos autores classificam como a população de baixa-renda, a maioria dos estudos mostram que é sobre o valor do rendimento das pessoas que vivem com uma quantidade limitada de dólares por dia, no Brasil o autor conceitua que são pessoas que pertencem às classes

O principal desafio para quem quer operar no mercado da base da pirâmide, é desenvolver o modelo de negócio mais adequado para a população de baixa-renda, as multinacionais já falharam ao entrarem nos países em desenvolvimento por terem um conceito de que poderiam apresentar um produto mais econômico, simples e acessível (BARKI, 2013, p. 29-30). Conforme De Soto (2000), citado por Barki (2013, p. 30) as multinacionais aprenderam que há existência de variáveis burocráticas, políticas, econômicas e sociais que influenciavam no contexto internacional.

Segundo Prahalad (2010, p. 28), o conceito da base da pirâmide foi incluído para "chamar atenção para os 4-5 bilhões de pobres não atendidos ou mal atendidos pelas grandes organizações do setor privado, entre elas as empresas multinacionais". Esses consumidores buscam a inclusão no seu processo de compra.

Das lições disseminadas, o autor identificou no período do estudo, foi que esses "micros consumidores e microprodutores" conseguem dar significância a um mercado em crescimento com inovação, dando início a um novo tipo de mercado para governo, gestores e sociedade civil (PRAHALAD, 2010, p. 29). Enfatizando que o "nosso objetivo deve ser criar condições para que as pessoas possam escapar da pobreza e da privação, mediante sistemas autossuficientes baseados no mercado" (PRAHALAD, 2010, p. 29).

Prahalad (2010, p. 49-50) esclarece que tem uma maneira de ajudar os pobres, como uma forma de envolver a inovação nesse mercado e de desenvolver o "ganha-ganha sustentável" em que as empresas conseguem desenvolver produtos e serviços lucrativos. O autor apresenta uma imagem sobre a base da pirâmide da seguinte forma:

Figura 2 - A pirâmide econômica.

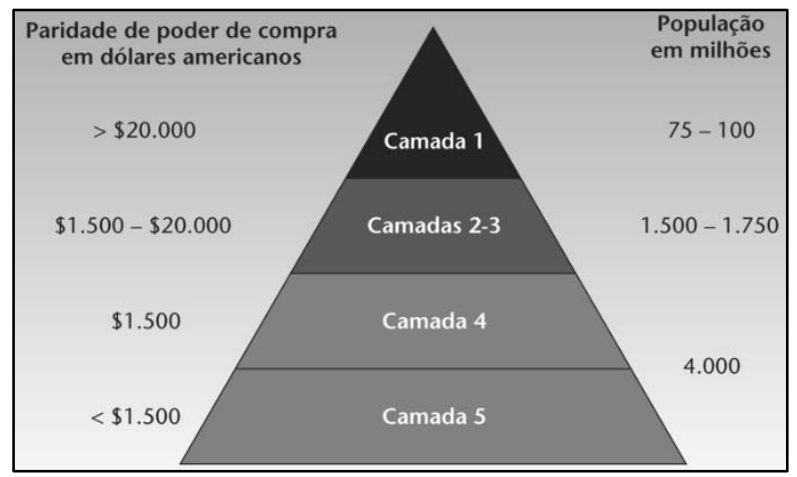

Fonte: Prahalad e Stuart (2002) citado por Prahalad (2010, p. 50).

No topo são os ricos, eles têm o maior poder econômico, mas a sua representatividade de população é pequena, enquanto na última camada, apresenta mais de 4 bilhões de pessoas que vivem na base da pirâmide com menos de $\$ 1.500$ dólares ao ano ou com menos de 2 dólares por dia (PRAHALAD, 2010, p. 50). 
Os modelos de negócios da base da pirâmide "devem ser inovadores e pensar fora da caixa" (BARKI, 2013, p. 31), para isso o autor identifica quais são os elementos básicos para que os negócios sociais possam ser bem desenvolvidos na base da pirâmide, segue abaixo a figura descrevendo os principais pontos que o autor relata em seus estudos:

Figura 3 - Elementos básicos de um modelo de negócio de sucesso para a Base da Pirâmide.

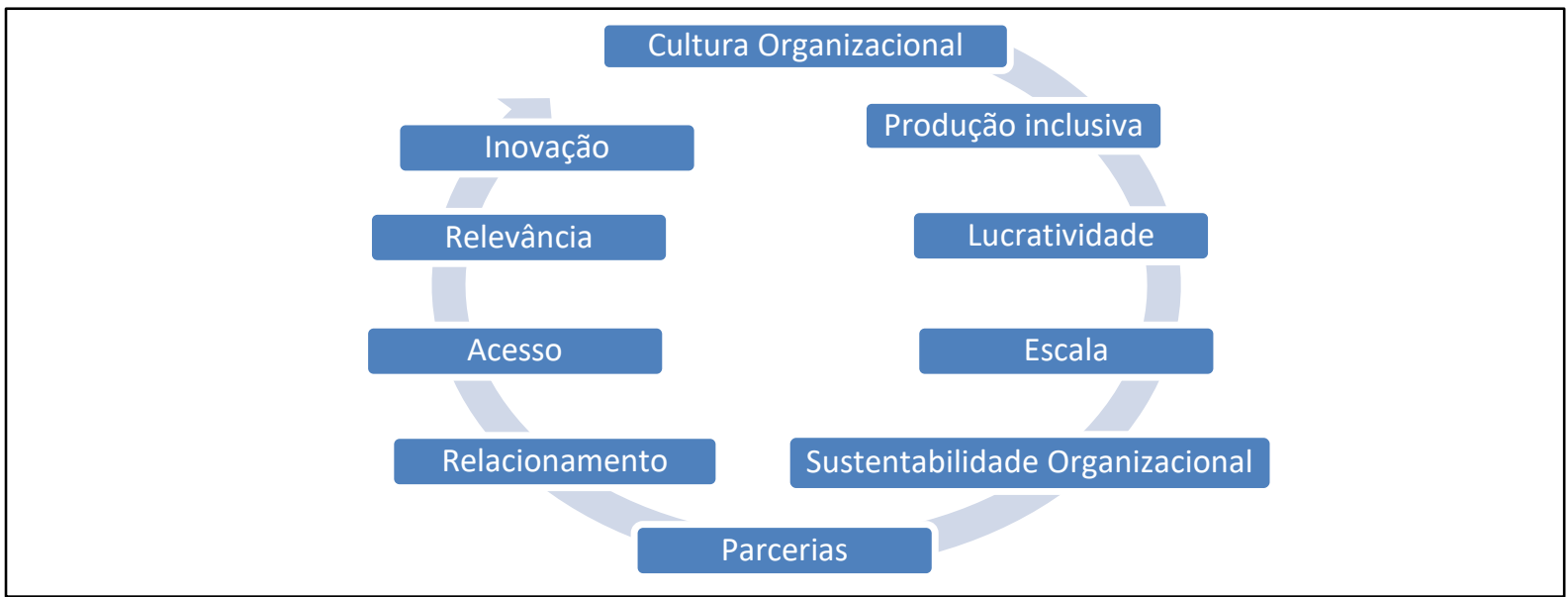

Fonte: Barki (2013, p. 31).

Os negócios com impacto social podem ser realizados por pequenas, médias e grandes empresas que queiram adaptar a esse modelo inovador de fazer negócios com impacto, principalmente social, o termo pode apresentar diferentes perspectivas, mas não deixam de ter sua lógica de mercado e sua lógica social (COMINI; BARKI; AGUIAR, 2013, p. 42).

Dentro disso, Comini, Barki e Aguiar (2013, p. 43-49) trabalham em três perspectivas para explicar as nomenclaturas dos negócios a base da pirâmide. A primeira perspectiva abordada, é a europeia, que tem como terminologia a "empresa social", na qual tem como propósito, negócios voltados para os desfavorecidos na sociedade, a segunda perspectiva abordada, é da américa latina, que usa a terminologia "negócios inclusivos" que tem como objetivo "empresas que geram mudança social por meio de atividades de mercado" (COMINI; BARKI; AGUIAR, 2013, p. 48). E a terceira perspectiva abordada, é "negócios com impacto social", em que se refere a empresa que tem objetivos sociais, mas apresenta-se como uma empresa tradicional para a obtenção de lucro e impacto simultaneamente.

Dessa forma os negocios que tem impacto social no seu propósito como empresa apresenta um novo modelo de organização ligado a inovação social. "A inovação social descreve todo o processo pelo qual novas respostas às necessidades sociais são desenvolvidas a fim de proporcionar melhores resultados sociais." (COMMISSION, 2013).

Para que esse modelo de negócio possa funcionar, Izzo (2013, p. 151) relata como seria a forma de financiamento dos negócios com impacto social no Brasil, sendo que é necessário fortificar ainda mais o conceito desse modelo, o autor questiona sobre as diferenças dos financiamentos tradicionais para o modelo apresentado, em termos de prazo de maturação da empresas e se o público alvo teria algum impacto na distinção do recurso.

Os negócios com impacto social têm um ciclo de vida dividido em 3 fases: start-up, crescimento e expansão. A primeira fase é quando a ideia do empreendedor, deixa de ser uma ideia e começa ser criada uma empresa que será testada no mercado. A segunda fase é de crescimento, quando seus produtos ou serviços começam a gerar receitas, mas ainda não dá 
para garantir se o modelo que está sendo aplicado será duradouro, a empresa tem que assegurar que ela possa se manter estável e lucrativa. A terceira e última fase é a de expansão, que é quando a empresa conseguiu sobreviver e a partir desse ponto ela poderá aumentar as vendas, diversificar o portfólio e etc (IZZO, 2013, p. 155).

Izzo (2013, p. 156), afirma que: "As principais fontes de financiamento de um negócio de impacto social não são muito diferentes dos oferecidos por uma empresa tradicional. Os atores, sim, podem ser distintos". Dinheiro próprio, dinheiro da família e de amigos, doações, empréstimos e participação acionária são alguns exemplos de financiamentos apresentados pelo autor (IZZO, 2013, p. 155-169).

Izzo (2013, p. 166), relata que os investidores que estão envolvidos procuram tanto o retorno social como financeiro. Uma solução para os empreendedores sociais, é de que eles possam procurar uma fonte de financiamento externo ao contexto brasileiro, junto com um plano bem elaborado e que estejam de acordo com visão e valores da empresa (IZZO, 2013, p. 169).

De Santana e De Souza (2015, p. 34), explicam que o lucro dos negócios tradicionais é diferente nos negócios sociais, justamente porque "o objetivo principal é gerar resultado social/ambiental positivo, tendo o lucro em segundo plano para suportar a criação de cada vez mais impacto com o decorrer das atividades."

Para os investidores, a situação não poderia ser outra, eles buscam principalmente o impacto, mas também querem o retorno financeiro (DE SANTANA; DE SOUZA, 2015, p. 34). Para isso em 2014, um estudo realizado pela Aspen Network of Development Entrepreneurs (ANDE), com a LGT Venture Philanthropy, Quintessa Partners e a Universidade de St. Gallen (2014), apresentaram uma visão dos investidores de negócios de impacto presentes no Brasil nos anos de 2003 a 2013, 68\% dos investimentos foram compostos por investidores estrangeiros e $32 \%$ por investidores nacionais.

Desses investidores, $89 \%$ estão com foco no setor de inclusão financeira, $84 \%$ no setor de educação, $63 \%$ setor da saúde e entre outros. Para a avaliação de escolha do investimento, $100 \%$ consideraram o impacto social como ponto chave para investir em uma empresa, seguida por $60 \%$ na qualidade de gestão e $55 \%$ em sustentabilidade financeira da empresa (MAPA, 2014).

\section{Análise dos Resultados}

A pesquisa foi realizada através de um roteiro de entrevista semiestruturada e aplicada com duas empreendedoras que possuem negócios com impacto social no Ceará, sendo realizada nos dias 29 e 30 novembro de 2018, uma entrevista foi feita por Skype e a outra foi presencial. O universo da pesquisa se limitou as respostas que foram adquiridas pelas empreendedoras. O roteiro de entrevista foi o instrumento metodológico utilizado para a coleta de dados e a elaboração do mesmo se deu através de identificar as questões sobre os negócios com impacto social presentes no Ceará.

Através das perguntas abertas do roteiro de entrevista, as entrevistadas poderiam explorar temas que estivessem envolvidos de acordo com a realidade de cada empresa. Como critério de confidencialidade as empresas estarão denominadas de acordo com o seu setor de atuação, Agricultura e Educação. As perguntas elaboradas foram direcionadas para os envolvidos na gestão, ambos os negócios foram fundados por mulheres que possuem 
formação acadêmica, uma tem carreira no terceiro setor e a outra tem envolvimento com empreendedorismo social desde da infância.

\subsection{Contextualização das empresas}

Em seguida serão apresentados um breve contexto sobre o surgimento e as realidades de cada empresa, realizadas de acordo com as entrevistas.

A empresa Agricultura foi criada dentro de um contexto familiar que procuraram atender a um mercado de alimentos sem agrotóxico por meio da agricultura familiar sustentável através da capacitação de agricultores familiares e o escoamento dos seus produtos através de feiras com o propósito de prover o comércio justo para o agricultor e o consumidor.

A ideia da empresa Educação nasceu através de uma professora que trabalhava na rede estadual de Fortaleza, pelo interesse em conhecer a realidade dos seus alunos que faziam parte da periferia da capital. A mesma descobriu que eles faziam projetos sociais na comunidade e sentiu interesse em conhecer e conseguir levar esses projetos para a dentro da sala de aula através do uso de plataformas virtuais de aprendizagem pela gamificação.

\subsection{Resultados da pesquisa}

Cada pergunta do roteiro de entrevista corresponde a um tema central que estão definidas nos quadros 2, 3 e 4 e que foram preenchidas de acordo com as respostas das empreendedoras sobre cada temática abordada. Os temas centrais para cada pergunta do roteiro de entrevista ocupam a primeira coluna, a segunda e a terceira coluna está representada as respostas das empreendedoras. Para apresentar o objetivo, serão demonstrados em três quadros, o primeiro quadro é sobre a estruturação de um perfil, o segundo quadro é sobre os tipos de impacto dos negócios com impacto social e o terceiro quadro é sobre a apresentação de seus trabalhos

O segundo quadro da pesquisa visa estruturar o perfil dos negócios com impacto social no estado, dessa forma está representado no seguinte quadro:

Quadro 2 - A estruturação do perfil dos negócios com impacto social no Ceará.

\begin{tabular}{|c|c|c|}
\hline Tema Central & Agricultura & Educação \\
\hline Início da ideia & 2016. & 2015. \\
\hline Processo de incubação & Não. & Sim. \\
\hline Equipe de gestão & 3 pessoas. & 4 pessoas. \\
\hline Investidores externos & Não. & Sim. \\
\hline Setor de atuação & Agricultura. & Educação. \\
\hline Natureza jurídica & $\begin{array}{l}\text { Microempreendedor individual } \\
\text { (MEI). }\end{array}$ & $\begin{array}{l}\text { Microempreendedor individual } \\
\text { (MEI). }\end{array}$ \\
\hline Intenção de impacto social & Sim. & Sim. \\
\hline Tecnologia & Sim. & Sim. \\
\hline Fonte de recursos & Recurso próprio. & Recurso próprio. \\
\hline
\end{tabular}




\begin{tabular}{|c|c|c|}
\hline Alcance de vendas & Sim. & Sim. \\
\hline Desafios/limitações & $\begin{array}{l}\text { 1) Comércio justo; 2) Impostos; } \\
\text { 3) Finanças. }\end{array}$ & $\begin{array}{l}\text { 1) setor do empreendedorismo é } \\
\text { muito hostil; 2) maturidade do } \\
\text { empreendedor; 3) jurídico e } \\
\text { contábil; 4) equipe treinada para } \\
\text { trabalhar com tecnologia. }\end{array}$ \\
\hline $\begin{array}{c}\text { Expectativa para os } \\
\text { próximos } 3 \text { anos }\end{array}$ & $\begin{array}{l}\text { Crescimento da equipe, aumento da } \\
\text { divulgação do marketing da empresa. }\end{array}$ & $\begin{array}{c}\text { Focar em escala, unificar os } \\
\text { serviços e conseguir ter algo mais } \\
\text { físico. }\end{array}$ \\
\hline
\end{tabular}

Fonte: Fonte da pesquisa (2018).

O início da ideia de criação das empresas se deu nos anos de 2015 e 2016. Fora questionado se a empresa passou por algum processo de incubação e se teve algum investidor externo, a empresa Agricultura não passou por esse processo, porém passou por um "processo de germinação" em uma universidade pública do sudeste do Brasil e todo investimento para o desenvolvimento da empresa foram provenientes de recurso próprio. A empresa Educação passou sim pelo processo de incubação, que teve duração de 10 meses, o investidor externo foi uma fundação fora do estado que fomenta empreendedores sociais pelo Brasil, antes disso a empresa tinha participado de uma pré-aceleração no sul do país.

Em relação a quantidade de componentes na equipe de gestão e a sua natureza jurídica, ambas têm aproximadamente quatro pessoas e estão reconhecidas juridicamente como microempreendedor individual, porém, a empresa Educação possui mais dez pessoas que trabalham como facilitadores que auxiliam nas atividades da empresa.

No que se refere ao nascimento da empresa com intenção de impacto social, ambas afirmaram que nasceram sim com essa finalidade.

No quesito ao uso de tecnologia no negócio, a empresa Agricultura utiliza um aplicativo que auxilia no escoamento da produção para o agricultor, e a empresa Educação utiliza a gamificação para interação dos usuários em seus cursos.

No que se refere se ao capital de sobrevivência da empresa atualmente, ambas conseguem manter a sua subsistência através do capital próprio faturado em suas vendas.

Sobre o alcance de vendas para outros estados ou cidades, a empresa Agricultura está presente em aproximadamente 20 cidades do estado no Ceará, essas são as cidades em que elas possuem agricultores, a empresa Educação já atuou em cidades que estão nos estados do Ceará, Pernambuco e Rio Grande do Norte.

Com relação aos desafios ou limitações que o negócio já passou desde do momento da idealização até o momento atual. A empresa Agricultura aborda que em primeiro a precificação do produto, devido ao entendimento do comércio justo, para que o negócio, sociedade e agricultor possam obter valores justos na cadeia, os impostos foi o segundo ponto abordado como desafio e o terceiro desafio da empresa é conseguir manter as finanças, porque elas lidam com o comércio justo para tentar obter lucratividade como empresa.

A empresa Educação abordou quatro desafios enfrentados nesse período de existência, a empreendedora aborda em primeiro, que o setor do empreendedorismo é muito hostil, devido questão de ter resistência para que o negócio possa conseguir se desenvolver, em segunda 
vem a maturidade do empreendedor para se manter ativo e operando em um ambiente que apresenta adversidades de mercado, em terceiro o jurídico e contábil já que a questão de ter que trabalhar com impacto social e por ser empresa e por último o treinamento da equipe de trabalho com o uso de tecnologia.

Ambas abordam a questão de ser uma empresa que trabalham com impacto e ter que pagar uma carga tributária muito elevada em comparação as empresas que não tem o mesmo objetivo de impacto social como elas.

As empresas são negócios que tem não apenas o intuito de conseguir ter recursos para a sua sobrevivência, mas também de impactar as pessoas envolvidas direta e indiretamente. Dessa forma, o terceiro quadro visa analisar qual é o principal tipo de impacto social que o negócio apresenta e poder explicar um pouco sobre como essas empresas mensuram seus impactos.

Quadro 3 - Principal tipo de impacto social do negócio.

\begin{tabular}{|c|c|c|}
\hline Tema Central & Agricultura & Educação \\
\hline Principal impacto & $\begin{array}{c}\text { Acessibilidade e preço justo para o } \\
\text { consumidor e para o agricultor. }\end{array}$ & $\begin{array}{c}\text { Desenvolver empreendedores sociais } \\
\text { nas comunidades. }\end{array}$ \\
\hline $\begin{array}{c}\text { Forma de Mensurar o } \\
\text { impacto atingido }\end{array}$ & Metodologia interna e externa. & Metodologia interna e externa. \\
\hline
\end{tabular}

Fonte: Fonte da pesquisa (2018).

Ao abordar qual é o principal impacto atingido e quais são as metodologias de mensuração de impacto que as mesmas utilizam. A empresa Agricultura tem como principal impacto poder viabilizar o acesso aos alimentos sustentáveis de forma que a sua comercialização seja justa tanto para o agricultor quanto para o consumidor. Como estratégias de mensuração de impacto a empresa desenvolveu alguma metodologia interna, para poder verificar se o agricultor atende os requisitos que a mesma determina, com isso a empresa pretende implantar uma metodologia francesa, o IDEA (Indicadores de Sustentabilidade das Explorações Agrícolas) para avaliar a sustentabilidade da agricultura familiar dos agricultores participantes e também implementar um selo para todo agricultor que for participar da empresa.

A empresa Educação abordou que o principal impacto é fazer com que a formação na comunidade possam desenvolver as habilidades do empreendedorismo social. Com isso a empresa utiliza metodologia científica a para medição de impacto, análise quantitativa e qualitativa em todos os programas da empresa, usam amostras de populações maiores para gerar dados e comparar com parâmetros nacionais e internacionais de impacto, usam métodos como teoria da mudança, tmd pro, estatística, grupos focais, entrevistas estruturadas, entrevistas não estruturadas para medir de forma qualitativa o impacto.

Os negócios com impacto social têm uma rotina de trabalho como qualquer outra empresa, o que irá diferenciar são os seus produtos e perfil do cliente, dessa forma, o quarto quadro visa apresentar a forma de trabalhos desses negócios. 
Quadro 4 - Forma de trabalhos desses negócios.

\begin{tabular}{|c|c|c|}
\hline Tema Central & Agricultura & Educação \\
\hline \multirow{2}{*}{ Produtos } & $\begin{array}{c}\text { Capacitação dos agricultores e } \\
\text { escoamento dos alimentos. }\end{array}$ & $\begin{array}{c}\text { Cursos em desenvolvimento de pessoas, } \\
\text { gerenciamento de projetos e design de } \\
\text { produtos. }\end{array}$ \\
\hline Perfil do cliente & Sem restrições de público-alvo. & Fundações, empresas e governo. \\
\hline
\end{tabular}

Fonte: Fonte da pesquisa (2018).

Ao debater sobre os produtos que as empresas vendem e qual é o perfil do seu público alvo. A empresa Agricultura tem como produto o alimento sustentável e faz o escoamento desses alimentos dos agricultores locais, que é feito através de feiras que estão espalhadas por Fortaleza, a empresa não tem restrições a apenas um público-alvo, o intuito é justamente é dar acessibilidade a qualquer consumidor.

A empresa Educação relatou que fazem um serviço e possuem três cursos voltados para jovens de 13 a 23 anos, que são sobre desenvolvimento de pessoas, gerenciamento de projetos e design de produtos, entretanto, os jovens são os consumidores, a empresa procura fechar com organizações (pessoas jurídicas), como fundações, empresas e governo, para que eles possam custear o curso e a empresa capacitar os jovens.

Pode-se observar que os quadros 2, 3 e 4 apresentaram o contexto e o perfil dos negócios com impacto social no estado, ambos foram fundados por mulheres. As entrevistadas deixaram claro nas entrevistas a dificuldade de fazer impacto social e obter lucro ao mesmo tempo, as empresas usam metodologias internas e externas de avaliação do impacto que querem atingir. Um dos pontos inovadores da empresa Agricultura é a questão de desenvolver um selo para que o agricultor possa participar e a empresa ter um melhor controle de qualidade nos seus alimentos sustentáveis. Já a empresa Educação um dos pontos inovadores é o fornecimento um modelo de educação através da gamificação para os jovens de 13 a 23 anos.

As duas empresas trabalham em contextos diferentes, porém, elas buscam atender o seu público alvo apresentando inovação social em seus processos, a empresa Agricultura procura fazer comércio justo na sua cadeia de produtos orgânicos e a empresa Educação procura alterar o contexto social dos jovens por meio da educação através de cursos usando a tecnologia.

O objetivo do estudo foi atingido durante a elaboração da pesquisa, o perfil dos negócios com impacto social existentes no estado fora apresentado, demonstrando as suas formas de trabalho, produtos, desafios, limitações, público-alvo, metodologias de mensuração de impacto e entre outras temáticas de trabalho das empresas.

\section{Considerações Finais}

A pesquisa permitiu analisar quais os perfis dos negócios com impacto social presente na região, dessa forma para responder a questão de pesquisa foi apresentada dois negócios, um atua no setor de Agricultura e outro em Educação, esses empreendimentos, apesar de 
serem recentes (ano 2015 e 2016) eles viabilizam a proposta de trazer uma metodologia inovadora que tenha a intenção de fazer impacto e ao mesmo tempo possuir lucratividade.

Murray, Caulier-Grice e Mulgan (2010) relatam que só uma minoria de ideias sobreviverá aos pilotos, o feedback do público e os métodos de avaliação são fundamentais para determinar o sucesso ou fracasso da empresa, para a inovação social se sobreviver é necessário que ela possa ter como uma das chaves principais conseguir ser sustentável, a empresa precisa apresentar uma estratégia voltada para sustentabilidade. "Precisa ser simples, persuasivo e marcante, pois, juntamente com a ideia social, é uma parte essencial de um empreendimento" (MURRAY; CAULIER-GRICE; MULGAN, 2010).

Dessa forma, os ambos os negócios têm natureza jurídica como microempreendedor individual, ambos foram fundados por mulheres e possuem uma equipe de gestão com aproximadamente 4 pessoas cada, as empresas adotam metodologias internas e externas para medição do impacto proposto. Os dois negócios passaram por um momento de viabilização da ideia, a empresa Agricultura sendo "germinada" por uma universidade pública no sudeste do país, e a empresa Educação passou por um momento de pré-aceleração na região sul, após isso, ela passou por um processo de incubação por uma fundação.

Os produtos da empresa Agricultura são alimentos sustentáveis, e que esses alimentos possam ser viabilizados para todas as classes sem ter restrições a um público alvo em si, pois o propósito é justamente poder facilitar o acesso a eles. A empresa Educação oferece cursos para o desenvolvimento de jovens, o seu público alvo são fundações, governos e empresas, que queiram introduzir o jovem nesse contexto da era da tecnologia, os cursos são feitos para eles, mas a forma de contrato só acontece de empresa para empresa.

Dada o interesse ao tema, torna-se necessário o desenvolvimento de negócios que possam resolver problemas encontrado no Ceará, e também o desenvolvimento de uma carga tributária com menos impostos para essas empresas que ajudam a solucionar algum problema social.

Contudo, os perfis dos negócios com impacto social no estado foram apresentados como uma forma difundir sobre a importância do tema e de apresentar como o contexto cearense está representado no Brasil.

\section{Referências}

ALVES, DIANA MARIA GOIANA. As relações sociais de trabalho, no contexto de negócios sociais, à luz da psicodinâmica do trabalho. 2018. Dissertação (Mestrado em Administração) - Centro de Estudos Sociais Aplicados, Universidade Estadual do Ceará, Fortaleza.

ARTEMÍSIA (Agenda Brasil do Futuro) (Org.). AVALIAÇÃo PARA NEGÓCIOS DE IMPACTO SOCIAL - Guia prático. 2017. Realização técnica: Move social. Disponível em: $<$ http://movesocial.com.br/wp-content/uploads/2017/11/2017_GuiaPr\%C3\%A1tico_Avalia\%C3\%A7\%C3\%A3o-para-Neg\%C3\%B3cios-de-Impacto-

Social_Artemisia_ABF_Move.pdf>.Acesso em: 14 nov. 2018.

BANCO MUNDIAL. World Development Report. Disponível em: <http://wdronline.worldbank.org/>. Acesso em 01 out. 2018.

BARKI, Edgard. Negócios de impacto: tendência ou modismo? GV-executivo, v. 14, n. 1, p. 14-17, 2015. 
BARKI, Edgard.; O mercado da base da pirâmide. In: Negócios com impacto social no Brasil. São Paulo: Peirópolis, 2013. cap.1, p.20-40. COMINI, Graziella.; BARKI, Edgard.; AGUIAR, Luciana. O novo campo dos negócios com impacto social. In 2013. cap.2, p.41-64. Negócios com impacto social no Brasil. São Paulo: Peirópolis,

COMINI, Graziella; BARKI, Edgard; DE AGUIAR, Luciana Trindade. A three-pronged approach to social business: A Brazilian multi-case analysis. Revista de Administração, v. 47, n. 3, p. 385-397, 2012.

COMISSÃO MUNDIAL SOBRE MEIO AMBIENTE E DESENVOLVIMENTO (CMMAD). Nosso futuro comum. Rio de Janeiro: Fundação Getulio Vargas, 1988.

COMMISSION, European. Guide to social innovation. 2013. Disponível em: http://s3platform.jrc.ec.europa.eu/documents/10157/47822/Guide to SocialInnovation.pdf. Acesso em: 16 nov. 2019.

CRESWELL, John W. Projeto de pesquisa: métodos qualitativo, quantitativo e misto. 3. ed. Porto Alegre: Ed. Artmed, 2010.

DE SANTANA, Ana Lúcia Jansen de Mello; DE SOUZA, Leandro Marins. Empreendedorismo com foco em negócios sociais. Curitiba: NITS UFPR, 2015.

FILHO, Gilberto R. Oliveira; KIYAMA, Renato Seiki; COMINI, Graziella. Os desafios de mensurar o impacto social. In Peirópolis, 2013. cap.10, p.211-235. Negócios com impacto social no Brasil. São Paulo: GIL, A. C. Métodos e técnicas de pesquisa social. 6. ed. São Paulo: Atlas, 2012.

GOMIDES, Andréa. Folha de S. Paulo. Híbrido de empresa e ONG, setor 2.5 ainda é apenas possibilidade no país.2018. Disponível em: $<$ https://www1.folha.uol.com.br/empreendedorsocial/colunas/2018/01/1945415-hibrido-deempresa-e-ong-setor-25-ainda-e-apenas-possibilidade-no-pais.shtml>. Acesso em: 10 nov. 2018.

IDIS. INSTITUTO DE DESENVOLVIMENTO SUSTENTÁVEL SOCIAL (Org.). Avaliação de Impacto Social metodologias e reflexões. 2018. Disponível em: $<$ https://www.idis.org.br/avaliacao-de-impacto-social-metodologias-e-reflexoes/>. Acesso em: 14 nov. 2018.

IZZO, Daniel. Fontes de financiamento. In Negócios com impacto social no Brasil. São Paulo: Peirópolis, 2013. cap.7, p.150-169.

JAPPE, MLM. Fatores Contributivos e fatores limitadores para negócios sociais no Brasil: Um estudo exploratório nas regiões sul e sudeste. 2013. 96 f. 2013. Tese de Doutorado. Dissertação (Mestrado em Administração), Universidade Federal do Rio Grande do Sul, Porto Alegre.

MALTHUS, Thomas Robert. An essay on the principle of population: or, A view of its past and present effects on human happiness. Reeves \& Turner, 1888.

MAPA. MAPA do setor de investimento de impacto no Brasil: resumo das conclusões. [S.1.], 2014.

Disponível

em:

<http://www.aspeninstitute.org/sites/default/files/content/upload/ImpactInvestingStudy_FINA L_VERSION_PORTUGUES.pdf >. Acesso em: 05 nov. 2018.

MURRAY, Robin; CAULIER-GRICE, Julie; MULGAN, Geoff. The open book of social innovation. London: National endowment for science, technology and the art, 2010. 
ONU. ONU diz que população mundial chegará a 8,6 bilhões de pessoas em 2030. 2017. Disponível em: <http://agenciabrasil.ebc.com.br/internacional/noticia/2017-06/onu-diz-quepopulacao-mundial-chegara-86-bilhoes-de-pessoas-em-2030>. Acesso em: 05 nov. 2018. PLANO, CDE. Mapeamento do campo de negócios sociais/negócios inclusivos.

Disponível

<https://assets.aspeninstitute.org/content/uploads/files/content/docs/ande/Mapping\%20Social \%20\&amp;\%20Inclusive\%20Businesses\%20in\%20Brazil\%20-

\%20complete\%20report\%2028_11.pdf > Acesso em: 05 nov 2018.

PNUD. As Perguntas Mais Frequentes sobre os Objetivos de Desenvolvimento Sustentável (ODS). Programa das Nações Unidas para o Desenvolvimento. 2018. Disponível em: <http://www.br.undp.org/content/brazil/pt/home/library/ods/cartilha-de-perguntas-erespostas-dos-ods.html>. Acesso em: 31 out. 2018.

PORTER, Michael E; KRAMER, Mark R. Criação de valor compartilhado. Como reinventar o capitalismo - e desencadear uma onda de inovação e crescimento. Harvard business review Brasil, JAN 2011. 16-32.

PRAHALAD, C.K. A riqueza na base da pirâmide: erradicando a pobreza com o lucro. Tradução André de Godoy Vieira. ed. rev. atual. Porto Alegre: Bookman, v. 5, 2010. 408 p.

ROSOLEN, Talita;; TISCOSKI, Gabriela Pelegrini.; COMINI, Graziella Maria. Empreendedorismo social e negócios sociais: um estudo bibliométrico da publicação nacional e internacional. In: DE SANTANA, Ana Lúcia Jansen de Mello, DE SOUZA, Leandro Marins. Empreendedorismo com foco em negócios sociais. Curitiba: NITS UFPR, 2015. p. $140-163$.

WHO. World Health Organization; UNICEF. United Nations Children's Fund. Progress on sanitation and drinking-water, 2010 update. Geneva: World Health Organization, 2010. Disponível

em:

<http://www.who.int/water_sanitation_health/publications/9789241563956/en/>. Acesso em: 01 out. 2018.

WHO World Health Organization; UNICEF. United Nations Children's Fund. Progress on Drinking Water, Sanitation and Hygiene: 2017. 2017. Disponível em: <http://www.who.int/mediacentre/news/releases/2017/launch-version-report-jmp-watersanitation-hygiene.pdf?ua=1>. Acesso em: 01 out. 2018.

YUNUS, Muhammad; DALSACE, Frédéric; MENASCÉ, David; FAIVRE-TAVIHNOT, Bénédicte. Como atender os consumidores mais pobres do primeiro mundo. Harvard Business Review, p. 24-31, 2015.

YUNUS, Muhammad; WEBER, Karl. Um mundo sem pobreza: a empresa social e o futuro do capitalismo. São Paulo: Ática, 2008. 